UDK: 655.3.022:004.9

DOI: https://doi.org/10.24867/05EF03Vesic

\title{
POSTOJANOST OTISAKA ŠTAMPANIH TEHNIKOM SITO ŠTAMPE PRI IZLAGANJU SPOLJAŠNJEM UTICAJU
}

\section{PERMANENCE OF PRINTS IN SCREEN PRINTING WHEN EXPOSED TO EXTERNAL INFLUENCES}

\author{
Katarina Vesić, Nemanja Kašiković, Ana Lilić, Fakultet tehničkih nauka, Novi Sad
}

\section{Oblast - GRAFIČKO INŽENJERSTVO I DIZAJN}

Kratak sadržaj - Rad obuhvata teorijske osnove sito štampe, $i$ istražuje promene koje nastaju prilikom izlaganja tekstilnih otisaka spoljašnjim uticajima, kao što su trljanje, delovanje toplote $i$ pranje. Promene koje nastaju vidljive su na pamučnom tekstilnom materijalu. Eksperimentalnim putem su utvrđene promene koje nastaju pri izlaganju otisaka spoljašnjim uslovima.

Ključne reči: Sito štampa, tekstil, trljanje, toplotno dejstvo, pranje, kontrola kvaliteta

Abstract - This paper presents the bases of screen printing as well as the parameters of evaluation of print quality. In the experimental part the results obtained by measuring of samples are presented and analysed. The aim is to determine the permanence of prints after being exposed to external influences.

Keywords: Screen printing, quality analysis of printed proofs, rubbing, thermal effect, washing prints

\section{UVOD}

Veliki broj raznih vrsta preduzeća i ustanova, svoje potrebe mogu zadovoljiti sa jednom relativno prostom štamparskom tehnikom poznatom pod nazivom sito štampa [1].

Kvalitet štampanog otiska u sito štampi zavisi od vrste materijala, vrsti boja koje se koriste i mnogim drugim parametrima važnim za sam proces štampe [2].

Sito štampa je tehnika štampe kod koje se otisak dobija tako što se boja potiskuje kroz delimično propustljivu štamparsku formu koja je zategnuta na ram. Štamparsku formu čini mreža na koju se postavlja šablon koji ima ulogu da zatvori određene elemente mreže, a da određene elemente ostavi otvorene [3].

Cilj istraživanja ovog rada odnosi se na utvrđivanje razlike između tri različitih vrsta pamučnih tkanina koje su odštampane na dve različite gustine sita, istom bojom, nakon procesa trljanja, toplotnog dejstva i pranja.

\section{EKSPERIMENTALNI DEO}

\subsection{Metode, materijali i uređaji}

U eksperimentalnom delu je analizirano koliko će se promeniti odštampani otisci na pamučnim materijalima,

\section{NAPOMENA:}

Ovaj rad proistekao je iz master rada čiji mentor je bio dr Nemanja Kašiković, vanredni profesor. koji su različitih debljina, nakon procesa trljanja, toplotnog dejstva i pranja uzoraka. Otisci uzoraka dobijeni su tehnikom sito štampe. Štampano je tri pravougaonika veličine $12 \times 4 \mathrm{~cm}$, na pamučnim tekstilnim materijalima koji su različitih debljina.

Uzorak 1 je najtanji materijal tzv. gaza; uzorak 2 je srednje deblji materijal tzv. posteljinski pamučni materijal i uzorak 3 je najdeblji materijal - keper. Prilikom štampe upotrebljena su dva sita različite gustine i to: $43 \mathrm{niti} / \mathrm{cm}$ i 120 niti/cm. Boja koja je korišćena za dobijanje otisaka je SERICOL PLASTIJET X1016/E0.

Uzorci su pre izlaganja spoljašnjim uticajima bili skenirani pomoću uređaja Canon CanoScan 5600F, a nakon svakog izlaganja uticaju ponovo su bili skenirani kako bi se prikazale razlike prilikom delovanja različitih uticaja.

Vrednosti reflektovane svetlosti, odnosno boja uzoraka pod standardnim osvetljenjem utvrđene su korišćenjem spektrofotometra HP200.

Za određivanje optičke gustine korišćen je TECHKON D61462 SpectroDens uređaj. Pomoću njega izmereni su uzorci nakon štampe, te nakon svakog uticajnog faktora kojem su uzorci bili izloženi.

Kako bi se utvrdila otpornost boje uzoraka na trljanje, korišćen je uređaj TESTEX TF411. Trljanje je izvršeno u tri serije $\mathrm{i}$ to od 50, 100 i 150 trljanja. Nakon svakog trljanja ponovo je skeniran otisak i izmerena optička gustina i merenje spektrofotometrijske vrednosti.

Izlaganje uzoraka toplotnom dejstvu, izvršeno je pomoću pegle, u tri serije, u trajanju od 1 minuta. Nakon svakog toplotnog dejstva ponovo je skeniran otisak i izmerena optička gustina i merenje spektrofotometrijske vrednosti. Pranje uzoraka, izvršeno je na temperaturi od $40^{\circ}$, u trajanju od 30 minuta, takođe u tri serije. Nakon svakog toplotnog dejstva ponovo je skeniran otisak i izmerena optička gustina i merenje spektrofotometrijske vrednosti.

\subsection{Rezultati i analiza rezultata nakon procesa trljanja}

Poređenje optičkih gustina različitih pamučnih materijala odštampanih na situ gustine $43 \mathrm{nit} / \mathrm{cm}$, nakon izlaganja uzoraka trljanju posle 50, 100 i 150 trljanja je prikazano na slici 1.

$\mathrm{Na}$ osnovu slike može se uočiti da se vrednost optičke gustine smanjuje nakon većeg broja trljanja što je i pravilno. Utvrđena optička gustina uzoraka odštampanih na situ gustine $43 \mathrm{niti} / \mathrm{cm}$, na uzorku 1 posle 50 trljanja iznosi 1,08 posle 100 trljanja 1,073 i posle 150 trljanja 1,066 . 
Na uzorku 2 iznosi posle 50 trljanja 1,096 posle 100 trljanja 1,086 i posle 150 trljanja 1,082 . Na uzorku 3 posle 50 trljanja iznosi 1,09 posle 100 trljanja 1,05 i posle 150 trljanja 1,04. Može se primetiti da je optička gustina na uzorku broj 2 najveća, a da je najmanja na uzorku broj 3, koji predstavlja najdeblji materijal.

\section{Optička gustina - sito 43 niti/cm}

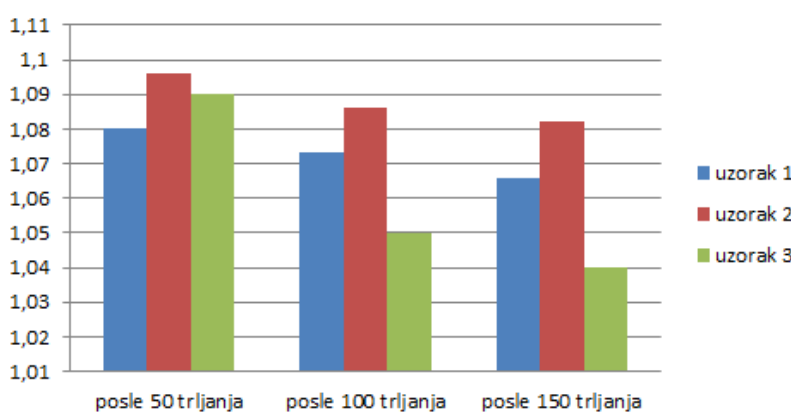

Slika 1. Poređenje optičkih gustina prilikom korišćenja sita sa gustinom tkanja od 43 niti/cm

Poređenje optičkih gustina različitih pamučnih materijala odštampanih na situ gustine $120 \mathrm{niti} / \mathrm{cm}$, nakon izlaganja uzoraka trljanju posle 50, 100 i 150 trljanja je prikazano na slici 2.

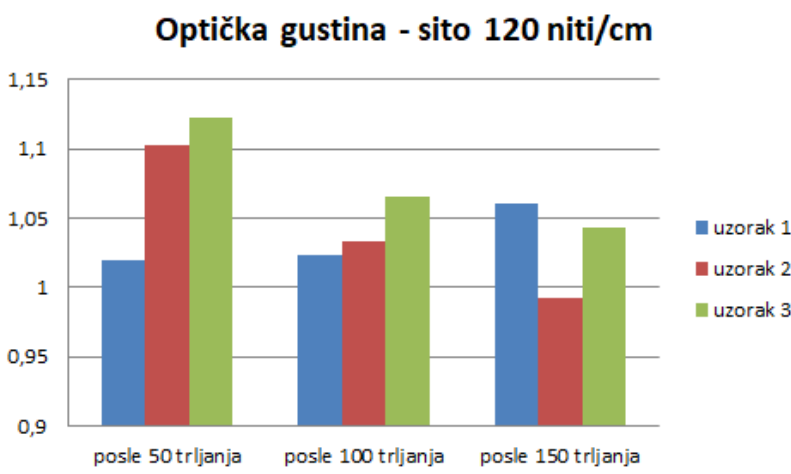

Slika 2. Poređenje optičkih gustina prilikom korišćenja sita sa gustinom tkanja od $120 \mathrm{niti} / \mathrm{cm}$

Na osnovu slike može se uočiti da se vrednost optičke gustine smanjuje nakon većeg broja trljanja što je i pravilno, dok se vrednosti na uzorku 1 povećavaju što nije dobro, moguće da merenja nisu izvršena na istim mestima, pa je to razlog ovih grešaka.

Utvrđena optička gustina uzoraka odštampanih na situ gustine $120 \mathrm{niti} / \mathrm{cm}$, na uzorku 1 posle 50 trljanja iznosi 1,02 posle 100 trljanja 1,023 i posle 150 trljanja 1,06 . Na uzorku 2 iznosi posle 50 trljanja 1,103 posle 100 trljanja 1,033 i posle 150 trljanja 1,993 . Na uzorku 3 posle 50 trljanja iznosi 1,123 posle 100 trljanja 1,066 i posle 150 trljanja 1,043. Može se primetiti da je optička gustina na uzorku broj 1 koji predstavlja najtanji materijal najveća, a da je najmanja na uzorku 2, koji predstavlja srednji materijal po debljini.

Prema formuli izveden je proračun razlike boja, slika 3 , između uzoraka odštampanih na situ gustine tkanja od 43 $\mathrm{niti} / \mathrm{cm}$.

Na osnovu slike može se uočiti da se vrednost razlike boja povećava nakon većeg broja trljanja i spada $u$ velike razlike koje ljudsko oko primećuje. Najveća razlika boje je na uzorku 2, a najmanja na uzorku 1.

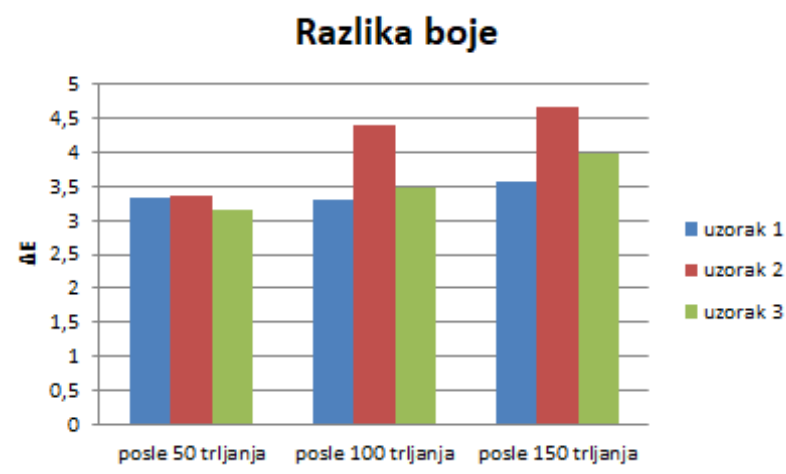

Slika 3. $\Delta$ E razlika boja prilikom korišćenja sita sa gustinom tkanja od 43 niti/cm

Razlika boje

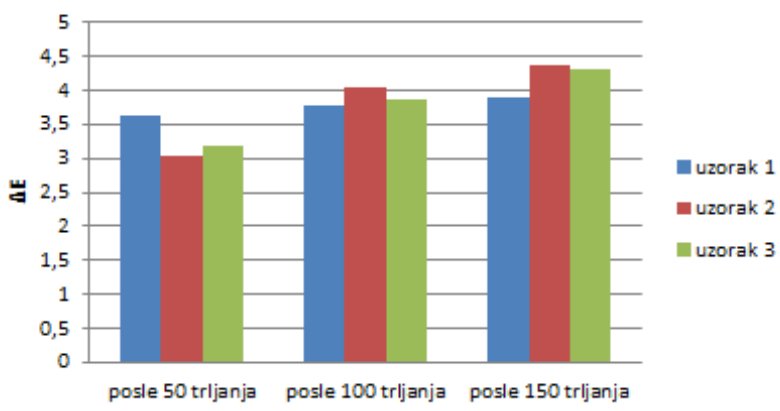

Slika 4. 4 E razlika boja prilikom korišćenja sita sa gustinom tkanja od $120 \mathrm{niti} / \mathrm{cm}$

Na osnovu slike može se uočiti da se vrednost razlike boja povećava nakon većeg broja trljanja i spada u velike razlike koje ljudsko oko primećuje. Najveća razlika boje je na uzorku 2 koji je srednje debeli materijal, a najmanja na uzorku 1 koji predstavlja najtanji materijal.

\subsection{Rezultati i analiza rezultata nakon delovanja toplote}

Poređenje optičkih gustina različitih pamučnih materijala odštampanih na situ gustine $43 \mathrm{nit} / \mathrm{cm}$, nakon izlaganja uzoraka toplotnom dejstvu od 1 minuta $u$ tri serije, na temperaturi od $110^{\circ} \mathrm{C}$, prikazano je na slici 5 .

\section{Optička gustina - sito $43 \mathrm{niti} / \mathrm{cm}$}

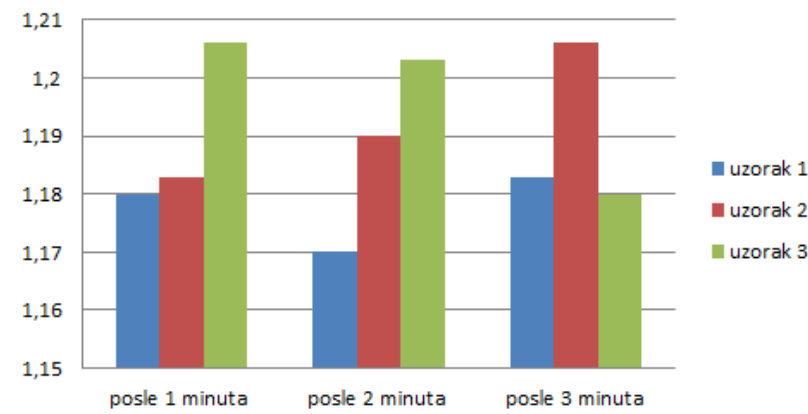

Slika 5. Poređenje optičkih gustina prilikom korišćenja sita sa gustinom tkanja od 43 niti/cm

Na osnovu slike 5, možemo uočiti da se vrednost optičke gustine $u$ nekim slučajevima smanjuje kao što je sa uzorkom broj 3, dok se na uzorku 2 vrednost optičke gustine povećava. Uzorak broj 1 posle izlaganja otisaka toplotnom dejstvu od 2 minuta ima nižu optičku gustinu, dok pri izlaganju uzoraka dejstvu od 3 minuta ima višu optičku gustinu. 
Poređenje optičkih gustina odštampanih na situ gustine $120 \mathrm{niti} / \mathrm{cm}$, nakon izlaganja toplotnom dejstvu prikazano je na slici 6 .

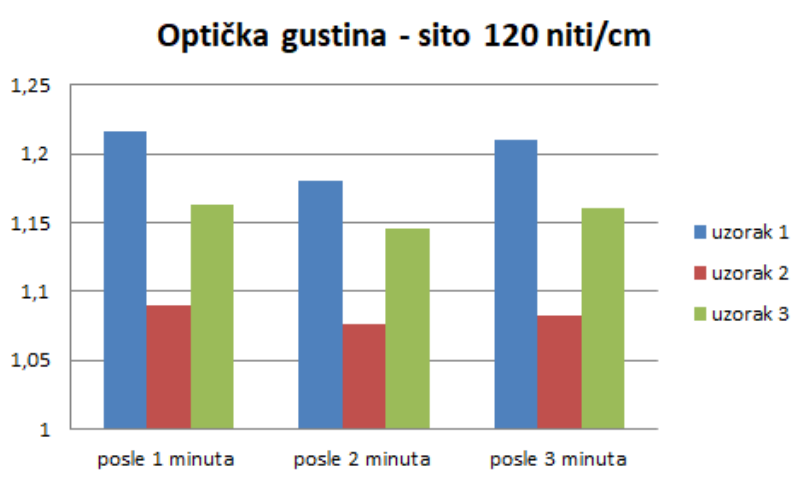

Slika 6. Poređenje optičkih gustina prilikom korišćenja sita sa gustinom tkanja od $120 \mathrm{niti} / \mathrm{cm}$

$\mathrm{Na}$ osnovu slike možemo uočiti da se vrednost optičke gustine na sva tri uzorka, posle toplotnog dejstva od 2 minuta smanjuje, za razliku od izlaganja otisaka toplotnom dejstvu od 3 minuta gde se optička gustina povećava.

Prema formuli izveden je proračun razlike boja, slika 7, između uzoraka odštampanih na situ gustine tkanja od 43 $\mathrm{niti} / \mathrm{cm}$.

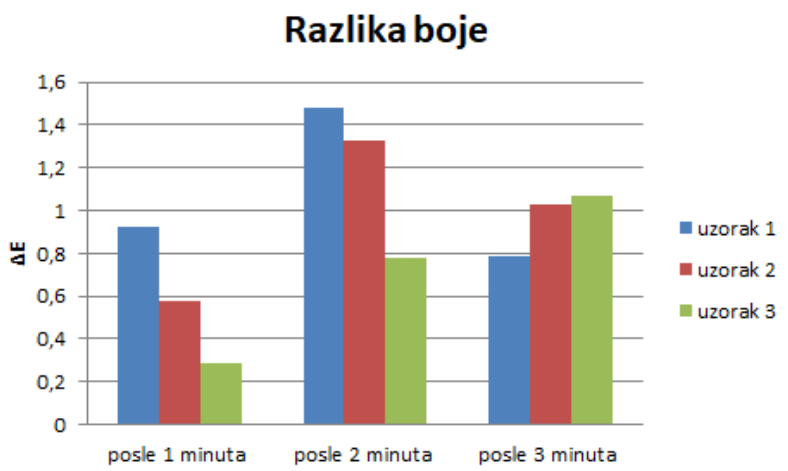

Slika 7. $\Delta$ E razlika boja prilikom korišćenja sita sa gustinom tkanja od $43 \mathrm{niti} / \mathrm{cm}$

Možemo uočiti da se vrednost razlike boje na uzorcima broj 1 i 2 povećava nakon 2 minuta delovanja toplotnog dejstva, zatim se smanjuje nakon delovanja 3 minuta toplotnog dejstva. Dok se na uzorku 3 vrednost razlike boja povećava nakon dužeg izlaganja uzorka toplotnom dejstvu.

Ova razlika boja na uzorcima, predstavlja malu razliku, koju može primetiti samo iskusno oko.

Prema formuli izveden je proračun razlike boja, slika 8 , između uzoraka odštampanih na situ gustine tkanja od $120 \mathrm{niti} / \mathrm{cm}$.

Može se uočiti da se vrednost razlike boje na svim uzorcima povećavaju nakon izlaganja toplotnom dejstvu. Na uzorku 2, razlika boje je najveća, dok je na uzorku 1 razlika boje najmanja.

Ova razlika boja na uzorcima, predstavlja veoma malu razliku koju može primetiti samo iskusno oko.

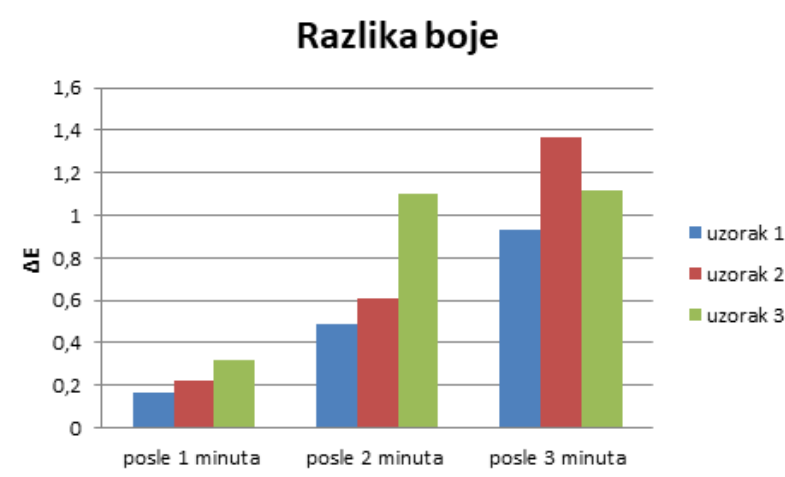

Slika 8. 4 E razlika boja prilikom korišćenja sita sa gustinom tkanja od 120 niti/cm

\subsection{Rezultati i analiza rezultata nakon procesa pranja}

Poređenje optičkih gustina različitih pamučnih materijala odštampanih na situ gustine $43 \mathrm{niti} / \mathrm{cm}$, nakon izlaganja uzoraka pranju na $40^{\circ}$, u trajanju od 30 minuta, u tri serije, prikazano je na slici 9.

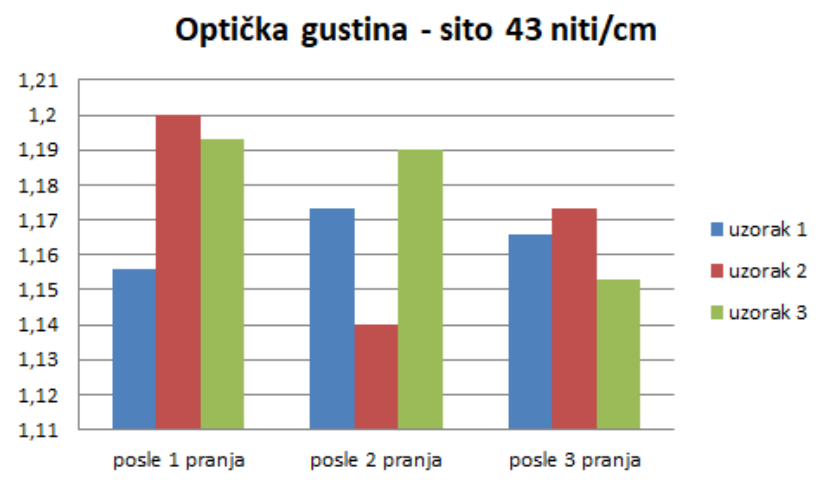

Slika 9. Poređenje optičkih gustina prilikom korišćenja sita sa gustinom tkanja od $43 \mathrm{niti} / \mathrm{cm}$

Na osnovu slike 9, može se uočiti da se vrednost smanjuje i povećava nakon većeg broja pranja. Pravilno je da vrednosti treba da opadaju, ali je moguće da merenja nisu izvršena na istim mestima, pa je to razlog ovih grešaka.

Poređenje optičkih gustina odštampanih na situ gustine $120 \mathrm{niti} / \mathrm{cm}$, nakon izlaganja uzoraka pranju, prikazano je na slici 10 .

Optička gustina - sito 120 niti/cm

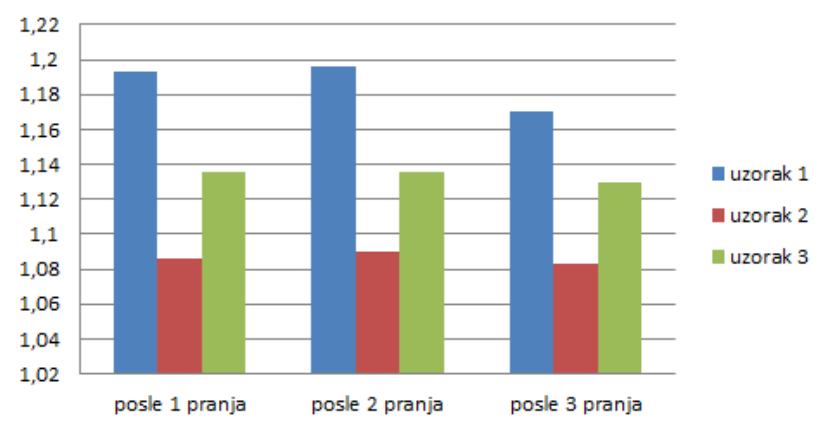

Slika 10. Poređenje optičkih gustina prilikom korišćenja sita sa gustinom tkanja od $120 \mathrm{niti} / \mathrm{cm}$

Na osnovu slike 10, može se uočiti da je vrednost nakon 2 pranja skoro ista kao i posle prvog pranja, a da optička gustina opada nakon trećeg pranja uzoraka. 
Prema formuli izveden je proračun razlike boja, slika 11, između uzoraka odštampanih na situ gustine tkanja od 43 niti $/ \mathrm{cm}$.

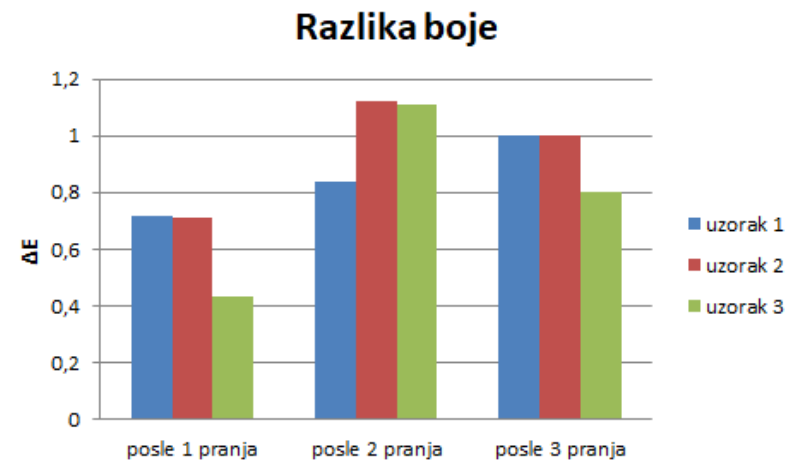

Slika 11. 4 E razlika boja prilikom korišćenja sita sa gustinom tkanja od $43 \mathrm{niti} / \mathrm{cm}$

Na osnovu slike 11, možemo uočiti da se vrednost razlike boje na uzorku 1 povećava nakon pranja, dok se na uzorku 2 i 3 vrednost razlike boje povećava nakon drugog pranja i opada posle trećeg pranja. Ova razlika boja na uzorcima, generalno ne može da se primeti.

Prema formuli izveden je proračun razlike boja, slika 12, između uzoraka odštampanih na situ gustine tkanja od $120 \mathrm{niti} / \mathrm{cm}$.

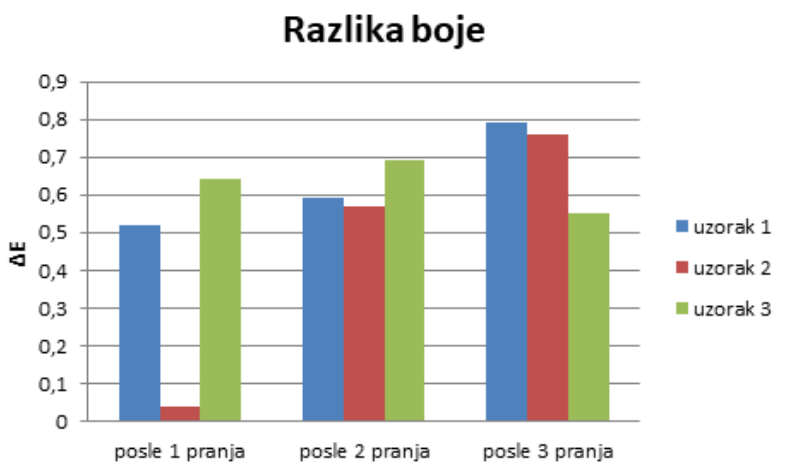

Slika 12. 4 E razlika boja prilikom korišćenja sita sa gustinom tkanja od 120 niti/cm

Na osnovu slike 12, može se uočiti da se vrednost razlike boje na uzorku 1 i 2 povećava nakon pranja, dok se na uzorku 3 vrednost razlike boja nakon prvog i drugog pranja povećava, a nakon trećeg pranja se smanjuje.

\section{ZAKLJUČAK}

Rad je imao za cilj da analizira uticaj različitih spoljašnjih faktora, procesa trljanja, toplotnog dejstva i pranja na izgled odštampanih otisaka. Ti uticaji su menjali CIE Lab vrednosti, optičku gustinu, i boju odštampanih pamučnih materijala koji su uzeti za analizu. Analiza je obuhvatala dve faze, stanje nakon štampe uzoraka, i analizu nakon procesa trljanja, toplotnog dejstva i pranja. Prikazani rezultati su pokazali da dolazi do promene u kvalitetu otiska na uzorcima nakon izlaganja procesu trljanja, delovanju toplote i pranja. Može se zaključiti da su najveće promene na pamučnim materijalima, nakon izlaganja procesu trljanja.

\section{LITERATURA}

[1] S. Janković, Mala škola sito štampe, prvo izdanje, Obrenovac, Srbija, Tehnička škola „Buda Davidović“

[2] D. Novaković, N. Kašiković, „Propusna štampa“, FTN izdavaštvo, Novi Sad, 2013.

[3] V. Konstantinović, A. Petrović, Osnovi grafičke tehnike, Zavod za udžbenike i nastavna sredstva, Beograd, 1999.

\section{Podaci za kontakt:}

\section{Katarina Vesić}

E-mail: k.vesic95@gmail.com

\section{dr Nemanja Kašiković}

E-mail: knemanja@uns.ac.rs

\section{MSc Ana Lilić}

E-mail: lilic.ana@uns.ac.rs 